\title{
On the Cover of this Issue: Reflected Near-Field Blast Pressure Measurements by S. E. Rigby, R. Knighton, S. D. Clarke, and A. Tyas
}

Published online: 30 July 2020

(C) Society for Experimental Mechanics 2020

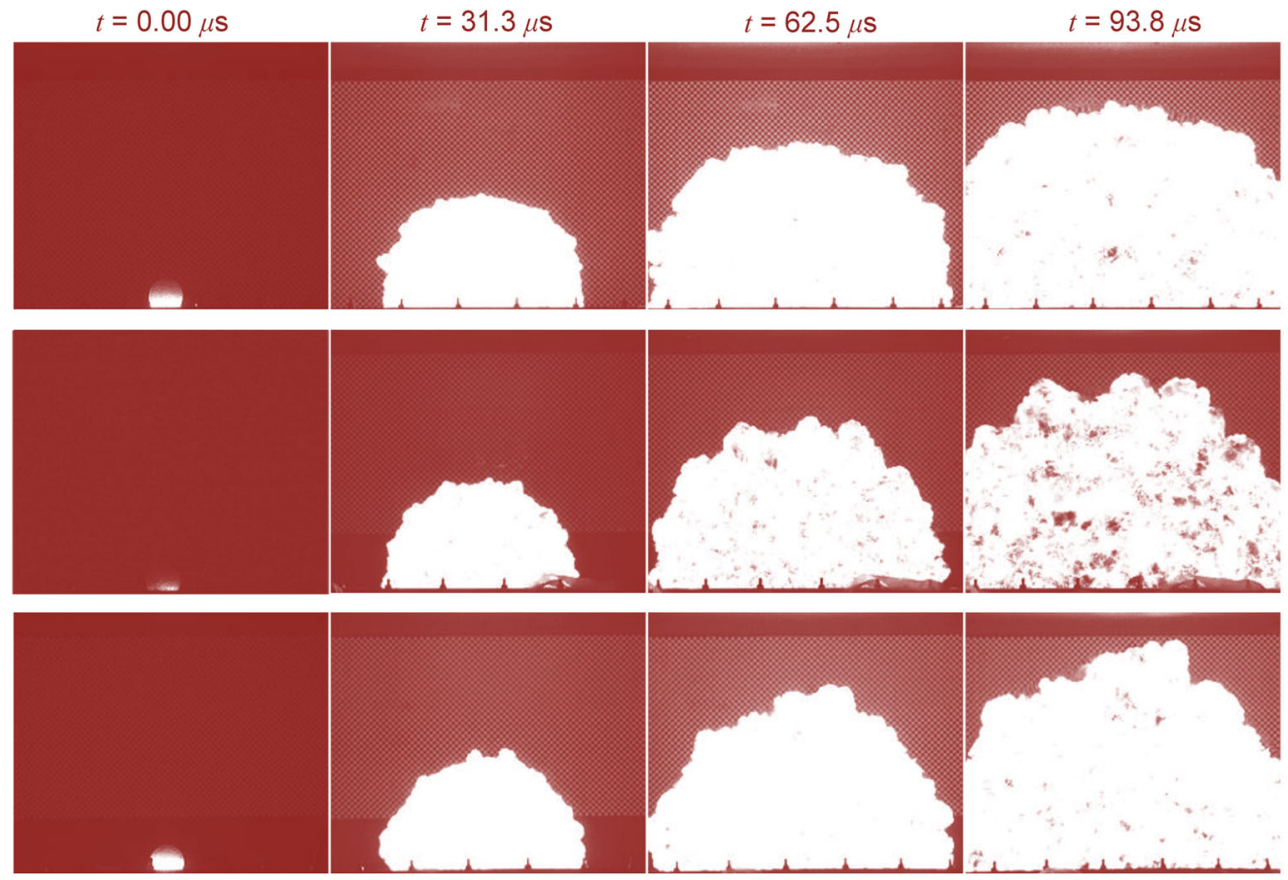

Reflected Near-field Blast Pressure Measurements

by S. E. Rigby, R. Knighton, S. D. Clarke, and A. Tyas

Publisher's Note Springer Nature remains neutral with regard to jurisdictional claims in published maps and institutional affiliations. 